\title{
Fandango Jovial d'un Tournant de siècle
}

\section{Habib Tengour}

URL : https://journals.openedition.org/coma/6251

DOI : $10.4000 /$ coma.6251

ISSN : 2275-1742

\section{Éditeur}

Institut des textes \& manuscrits modernes (ITEM)

\section{Référence électronique}

Habib Tengour, « Fandango Jovial d'un Tournant de siècle », Continents manuscrits [En ligne], 15 | 2020, mis en ligne le 15 octobre 2020, consulté le 13 janvier 2023. URL : http://journals.openedition.org/ coma/6251 ; DOI : https://doi.org/10.4000/coma.6251

Ce document a été généré automatiquement le 13 janvier 2023.

\section{(c) (i) (9)}

Creative Commons - Attribution - Pas d'Utilisation Commerciale - Pas de Modification 4.0 International - CC BY-NC-ND 4.0

https://creativecommons.org/licenses/by-nc-nd/4.0/ 


\title{
Fandango Jovial d'un Tournant de siècle
}

\author{
Habib Tengour
}

\section{NOTE DE L'AUTEUR}

Ce texte, je l'ai écrit Frédéric Jacques Temple vivait encore. Depuis trois ans, nous avions pris l'habitude de nous envoyer des poèmes acrostiches pour nous souhaiter un joyeux anniversaire. J'allais envoyer mes vœux quand j'ai appris le décès de Frédéric Jacques Temple. J'étais tellement persuadé qu'il allait encore vivre cent ans, qu'on allait célébrer dans la joie son centenaire, que ce fut un choc...

Je garde en mémoire la belle rencontre en novembre 2019, à la maison de la poésie de Montpellier pour présenter son recueil Poèmes en archipel, publié à Alger aux éditions Apic. Nous avions discuté de poésie et de Mohammed Dib qu'il avait connu. Frédéric Jacques Temple était si plein de vie et de vivacité ! (Le Kremlin-Bicêtre, 11 octobre 2020).

1 Fredaines fantômes à mi-chemin du jour Rappelant l'impatience des passereaux Quand se précise l'heure de la migration

2 Jubilation sur les branches des platanes Ton regard transperçant les ombres Attablées sous un parasol

3 Terre et ciel abdiquant toute tension Se consultent pour trouver mesure du chant Propice au siècle qui s'annonce 
René Laubiès, Composition II

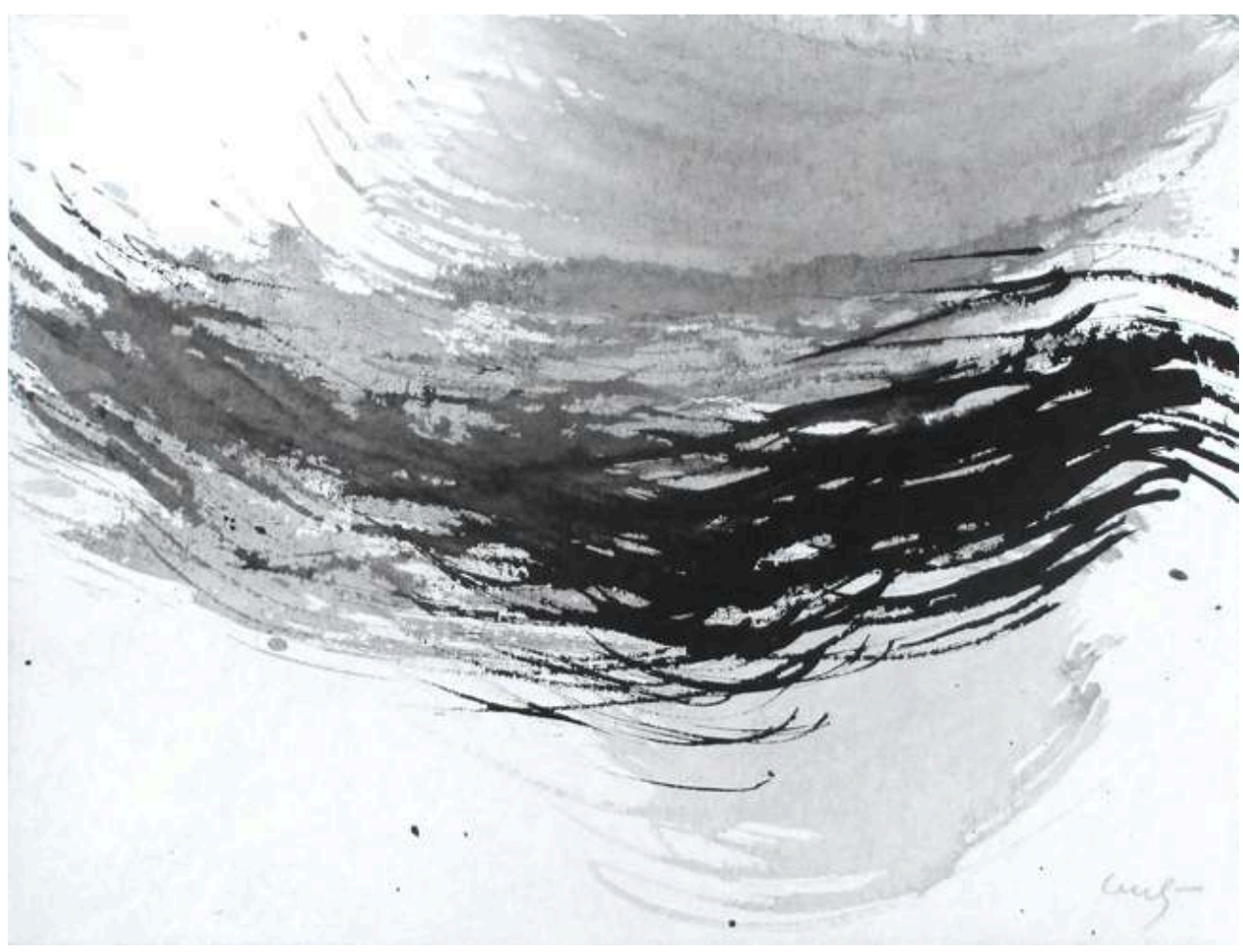

INDEX

Mots-clés : poésie francophone algérienne, inédit

\section{AUTEUR}

\section{HABIB TENGOUR}

Écrivain, poète et sociologue algérien né à Mostaganem le 29 mars 1947. 